\title{
An Action Research on Improving the Interest of Students Toward Practical Sessions: First Year Animal Production and Technology Department in CANR, Wolkite University, Ethiopia
}

\author{
Aderajew Gebrie $^{1} \quad$ Mekash Teferra ${ }^{2}$ \\ 1.Wolikite University, Department of Agricultural Economics, P.O.Box 07, Ethiopia \\ 2.Debark University, Department of Agricultural Economic, Ethiopia
}

\begin{abstract}
Education play great role and contributes to economic grow as well as economic development in Ethiopia. Therefore, this study aimed to analyzing interest of students toward practical session of first year animal production and technology department in CANR, Wolikite University. The specific objective of study was to assess the interests of student towards practical session active participation, to identify factors that determine student participation interests in practical session and to improve the active participation of students in practical session. The study was based on cross-sectional data collected from 32 first year animal production and technology student in Agriculture College, Wolikite University Ethiopia. For data collection, personal student observation in practical session class, focus group discussion and questioner were used. Descriptive and econometric model with STATA version 14 were used for data analysis. As descriptive statistics result revealed that about 37.5 percent of the respondents were always participate in practical classes and the remaining 62.5 percent attends practical classes sometimes. From 32 student, 46.9 percent of the students revealed that their instructors provided different encouragement advice on practical classes. The remaining 53.1 percent have reported that they have not got encouragement advice from their instructors. From the actively participating students, 60 percent believed that active participation in practical classes was excellent while 33.3 percent and 6.7 percent believed that practical session was very good and good respectively. From the total sampled student, 56.3 percent believed that active participation in practical sessions help to improve the knowledge of course while 43.7 percent was in doubt of it and thus asserting that active participation has nothing to do with improving knowledge. According to the estimated logit model indicated, attitudes toward practical classes, attitudes for practical classes to improving the course knowledge were positively and statically significant at 10 and5 percent respectively. But the marginal effect of participation frequency affected active participation in practical classes negatively at 5 percent of probability level. After taken different intervention strategy, as table 3 show that the average score of the student with in quiz from 5percent was 3.14 and 3.79 before and after implementation of our intervention respectively and also the average score of the overall student within their own test result was 5.84 percent and 7.07pecent before and after implementation of our intervention respectively.
\end{abstract}

Keywords: Action Research, Logit Model

DOI: $10.7176 / \mathrm{JEP} / 12-13-02$

Publication date:May $31^{\text {st }} 2021$

\section{Introduction}

\subsection{Background of Study}

Education sector is one of the pillar tools which play a key role for the economic growth and development in Ethiopia. Currently, Ethiopia is enchanting different measures to use education for the source of economic growth and development. Strategies taken so far by the Ethiopian government to increase, the number of educated person includes; expanding the number of university, colleges, institutes and schools which can support the country for its development.

However, availability of different education sector is not sufficient method of education quality enhancement. Among the number of quality education enhancement method, active learning method plays pivotal role. As such, Wolikite University has been adopted active learning methods which are now being practiced widely. As Biggs (2003) suggests, active learners are able to achieve a higher level of engagement and thus a higher level of cognitive learning in their academic work. Doing this action research on how to improve the interest of student to the practical session, help to make possible the learning- teaching process easy in CANR (College of Agriculture and Natural Resource) with in animal production and technology department. As result this study is expected, when students interact more intensely their practical session, which leads improve student performance.

\subsection{Statement of the problem}

Education has been transformed as to be a means for achieving good performance on student and when this can be applied by implementing active learning methods. In the earlier times students are considered as to be an empty poet that the teacher will fill knowledge by lecture method without an active involvement of students in the 
practical session, so that they have a few chances for participation and discussion in the classroom. Therefore, use active learning methods leads students will interact with their teacher and discuss with their classmate. Now the Ministry of Education (MOE) is advocating active learning approach in all universities including Wolikite University. But when we come WKU particularly in CANR in animal production and technology department, Even if we are using some active learning method, according to our exploratory study result all students are not consistently participate in their practical session and not summit their practical report on time, due to contributed by different factors like class size, class schedule, lack of awareness of teachers to use active teaching methods, students perception about education is duty of only teachers. Therefore, we hereby concerned on soughing solutions and up grading the interest of students through stretch suitable learning mechanisms.

\subsection{Research Questions}

The following questions were sated as a research questions:

1. What are the interests of students' participation in practical classroom?

2. What factors determine student participation interests in the practical class room?

3. Why students' participation becomes low in the practical classroom?

\subsection{Research Objectives}

The general objective of the study is "to improve the interest of students toward practical session of first year animal production and technology department in CANR, Wolikite University.

\subsection{Specific Objectives of the Study}

From the general objective, the following specific objectives are listed. These are

1. To assess the interests of students towards practical session participation

2. To identify factors that determines student participation interests in practical session

\subsection{Hypothesis of Study}

The study hypothesizes that frequency of participation, student attitudes of practical session, time suitability for practical sessions, method of teaching, and their awareness towards the potential benefits of practical session, have no statically significant relationship with students active participation interests in practical session.

\subsection{Significant to Study}

Improving practical session is very importance for students to increases their skill to put theoretical knowledge into practices, deep understanding of the subject matter and execute research on subject matter. Improving and link between theories and practice; students can learn the scientific attitude of taking and analyzing data patiently and accurately. Hence, searching the factors which lead students are not consistently participates within their practical session and not summits their practical report on time in animal production and technology and taking suitable answers (action) accordingly will be our initial focus. In general, to solve the above problem enforce us to write this action research by this specific title; Improve the interest of students toward practical session of first year animal production and technology department in CANR.

\subsection{Scope and Limitation of Action Research}

From the type of research matter this study was used action research with cross sectional data and first year animal production and technology department. Therefore, the outcome and end drawn in the study may not represent the practices teaching for other college and department. Also the students may be doubtful to give correct information on their interests to participate practical class room due to fear of their grade. Some limitation of this study may be occurring due to the study assume that all availability lab material is remain constant, shortage of budget and time to collect available information at specific period of time.

\section{Literature Review}

\subsection{Theoretical Literature Review}

\subsubsection{Definition of action research}

Action research is a process in which participants examine their own educational practice systematically and carefully, using the techniques of research (Watts, 1985).

Action research emphasizes the involvement of teachers in problems in their own classrooms and has as its primary goal the in-service training and development of the teacher rather than the acquisition of general knowledge in the field of education (Borg, 1965).

"Action research is the study of a social situation with a view to improving the quality of action within it." (Elliot, 1991)

Action research is a collaborative, cyclical process, strategic planning, action implementing the plan and 
observation, evaluation and self-evaluation, critical and self critical reflection on the results and change in social, cultural, political systems" (Brody, 2006).

Mills (2003) gives the following definition of teacher action research: "Action research is any systematic inquiry conducted by teacher researchers to gather information about the ways that their particular school operates how they teach, and how well their students learn. The information is gathered with the goals of gaining insight, developing reflective practice, effecting positive changes in the school environment and on educational practices in general, and improving student outcomes."

Action research differs from other types of research in at least four ways. First, it embeds the researcher into the practices of the people involved. The teacher-researcher is inclined to learn more and be more willing to apply what he or she learns, when they do something themselves. So action research has a good chance of changing teacher practice. Second, action research has a social dimension often not seen in other forms of research. The research takes place in everyday situations and is aimed at improving everyday problems in the classroom or in the school. Third, the initiating researcher does not need to remain completely objective. They can openly acknowledge their biases to other participants. Fourth, this type of research is more likely to have lasting effects on the group involved because often the group is involved in the change that is taking place.

\subsubsection{Types of Action Research}

There are different types of action research depending upon the participants involved. A plan of research can involve a single teacher investigating an issue in his or her classroom, a group of teachers working on a common problem, or a team of teachers and others focusing on a school- or district-wide issue.

Individual teacher research usually focuses on a single issue in the classroom. The teacher may be seeking solutions to problems of classroom management, instructional strategies, use of materials, or student learning. Teachers may have support of their supervisor or principal, an instructor for a course they are taking, or parents. The problem is one that the teacher believes is evident in his or her classroom and one that can be addressed on an individual basis.

Collaborative action research may include as few as two teachers or a group of several teachers and others interested in addressing a classroom or department issue. This issue may involve one classroom or a common problem shared by many classrooms.

School-wide research focuses on issues common to all. For example, a school may have a concern about the lack of parental involvement in activities, and is looking for a way to reach more parents to involve them in meaningful ways. Teams of staff from the school work together to narrow the question, gather and analyze the data, and decide on a plan of action. An example of action research for a school could be to examine their state test scores to identify areas that need improvement, and then determine a plan of action to improve student performance.

District-wide research is far more complex and utilizes more resources, but the rewards can be great. Issues can be organizational, community-based, performance-based, or processes for decision-making. A district may choose to address a problem common to several schools or one of organizational management. Downsides are the documentation requirements (communication) to keep everyone in the loop, and the ability to keep the process in motion. Collecting data from all participants needs a commitment from staff to do their fair share and to meet agreed-upon deadlines for assignments. Within all the definitions of action research, there are four basic themes: empowerment of participants, collaboration through participation, acquisition of knowledge, and social change. In conducting action research, we structure routines for continuous confrontation with data on the health of a school community. These routines are loosely guided by movement through five phases of inquiry, such as identification of problem, collection and organization of data interpretation of data, action based on data and reflection.

\section{Research Methodology}

\subsection{Target Group}

The target groups of this research were first year animal production and technology students which were 32 in number. First year students were selected due to the study expectated that, they would be benefited more from the results of the research than the second and third year students as they are remaining with two years to graduate.

\subsection{Research Design}

The study used both qualitative and quantitative type of research data with cross sectional data collection and with help of distributive research design, because both numerical and non-numerical data is available to accomplish the study.

\subsection{Sampling Technique and Sample Size}

In order to attain an accurate qualitative and quantitative cross-sectional data from students in CANR, From 8 department, animal production and technology department was purposively selected because of the availability of information regarding to students. Even though the study department comprises of first, second and third year student, first year students will be purposive select. Due to the number of student is small, all (32) first year animal 
production and technology students were sampled purposely and then by using this sample the study describe different characteristics of student. Finally after understanding and identify the problem from final research result of the study, intervention will be apply to enhancing students in their practically session.

\subsection{Source of Data}

The study used both primary and secondary data. The primary data were collected through observation, FGD and personal interviews with using structured interviews schedules from first year animal production and technology students. The secondary type of data like published data from books, journals and unpublished data from department documents will be collects.

\subsection{Method of Data Collection}

Qualitative and quantitative data were collected through observation for their participation relative to many different factors and FGD for qualitative data and also questionnaire will be use for quantitative data.

\section{Observation}

We observed the students whether they were participating in practical session or not. During our observation we have seen interest, feeling and responsibility e of student for their work.

\section{FGD and individual reflection}

We provided questions on the discussion point to be answered by the group members after practical session. And then, we gave them a chance to respond the same question individually. It helped us to crosscheck whether they have good participate in the session equally or not in the morning and afternoon. Hence, we came up to know that the group and individual reflection are more or less close to each other, which is an evidence for their participation.

\section{Questionnaire}

We distributed questionnaires for students, related to interests to participation during the session class, time at which the practical session used, student and teacher relationship, method of teaching they have been using, their attitudes for practical session and others.

\subsection{Method of Data Analysis}

The data, collected through observation, FGD and questionnaire with in specific research questions were analyzed using both descriptive and econometric procedures of data processing. Descriptive statistics, incorporating; frequencies, percentages, and tabular analysis were used to examine and understand the situations of sampled respondents descriptive statistics' with in STATA version14.

The core aim of this investigation was to understand the interests of students toward practical session participation. The dependent variable representing interests of students toward practical session participation is a dummy variable that takes a value of one for who have interest to participate actively or zero for who have not any interest to actively participate in practical session. This binary variable will related to several sets of factors (continuous, discrete and dummies) that are we believed to influence interest of student to participate in practical session.

\subsection{Econometric Model Specification}

Following Gujarati (1988) and Maddala (1992), the logistic distribution for interest of student to participate in practical session can be specified as:

$$
\mathrm{P}_{\mathrm{i}}=\frac{1}{1+e^{-z}}
$$

Where $\mathrm{P}_{\mathrm{i}}$ is the probability of interest to participate in practical session each student and ranges from 0 to $1 . \mathrm{Z}_{\mathrm{i}}$ is the function of a vector of $n$ explanatory variables which influence their interest to participate in practical session and expressed as:

$\mathrm{Z}_{\mathrm{i}}=\mathrm{B}_{0}+\sum \mathrm{B}_{\mathrm{X}} \mathrm{X}$

Where $B_{o}$ is the intercept and $B_{i}$ is a vector of unknown slope coefficients.

The relationship between $\mathrm{P}_{\mathrm{i}}$ and $\mathrm{X}_{\mathrm{i}}$, which is non-linear, can be written as follows

$$
\mathrm{P}_{\mathrm{i}}=\frac{1}{1+e^{-(B 0+B i X i \ldots \ldots \ldots . . . B n \times n)}}
$$

The slopes tell how the log-odds in favor of interest to participate in practical session changes as independent variables change. If $P_{i}$ is the probability of interest to participate in practical session, then 1- $P_{i}$ represents the probability have not interest to participate in practical session and can be written as:

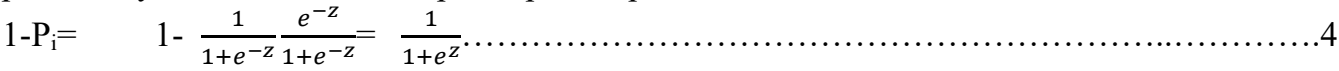

Dividing equation (1) by equation (4) and simplifying gives:

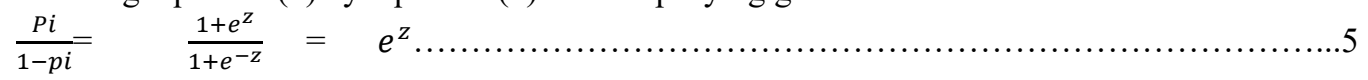

Equation (5) indicates simply the odd-ratio in favor of interest to participate in practical session. It is the ratio of the probability that the student will interest to participate in practical session to the probability that he will not 
interest to participate in practical session. Finally, the logit model is obtained by taking the logarithm of equation (5) as follows.

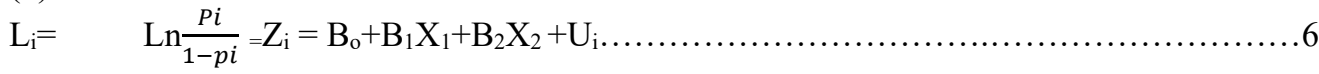

This econometric model was used in this study, and variables that were assumed to influence the interest to participate in practical session were tested. The parameters $\left(B_{i}\right)$ of the model were estimated using Maximum Likelihood Estimation (MLE) procedure due to the nonlinearity of the logistic regression model. The MLE procedure yields unbiased, asymptotically efficient, and normally distributed regression coefficients (parameters). The logistic regression slope coefficient can be interpreted as the change in the log odds associated with a one-unit change in the independent variable $\left(\mathrm{X}_{\mathrm{i}}\right)$.

The study hypothesized that student interest to participate in practical session are influenced by students attitude towards practical session, teaching method, student encouragement ,participation frequency, Students' perception of whether practical can improve knowledge, suitability of time they are taking their practical session method of teaching, and their awareness towards the potential benefits of practical session and active learning methods.

\section{Results and Discussion}

\subsection{Results of the Descriptive Statistics}

The descriptive analysis revealed that about 37.5 percent of the respondents always participate in practical classes. The remaining 62.5 percent attends practical classes sometimes. This indicates that majority of the students do not attend practical classes on regular basis. Dis aggregating this, among those who do not actively participate in practical classes, 88.2 percent attends sometimes while only 11.8 percent were attending always (on regular basis). On the other hand, among those who actively participate in practical classes, 66.7 percent were attending practical classes always while 33.3 percent were participating sometimes. Relatively, the proportion of students participating in practical classes regularly was higher $(66.7 \%>11.8 \%)$ among the actively participating students compared to those of not actively participating.

As deduce that the higher the frequency of attending practical classes on regular basis, the more would be the possibility of actively participating in practical classes. The proportional difference among the groups of actively participating and not actively participating was statistically significant at 1 percent significance level.

Regarding encouragements, overall, 46.9 percent of the students reported that their instructors give them encouragement advice on practical classes. The remaining 53.1 percent have reported that they have no got any encouragement advice from their instructors. From the actively participating students, 66.7 percent have got encouragement advice by their teacher, where as the proportion 29.4 percent among the non-actively participating students have got encouragement advice by their teacher.

The proportion of having encouragement from instructors was higher among the actively participating students indicating that, students who get encouragement from their teachers participate more in practical classes actively compared to those without encouragements. The difference was statistically significant at 1 percent significance level.

In relation to attitudes towards practical classes, among the actively participating students, 60 percent believed that active participation in practical classes is excellent while 33.3 percent and 6.7 percent believed that practical session is very good and good respectively. Among the non- actively participating students, 41.2 percent, 5.9 percent, and 52.9 percent believed that practical sessions were excellent, very good and good respectively. The higher proportion of students believing that practical session was good among the non-actively parting students compared to that of actively participating student. The proportional difference among the actively participating and non-actively participating was statistically significant at 1 percent significance level. From the total sample, 50 percent of the students believed that practical sessions were excellent while the remaining 18.8 percent and 31.2 percent believed that practical sessions were very good and good respectively.

Students' perception of whether practical sessions can improve their knowledge of the course, From 32 students 56.3 percent believed that active participation in practical sessions help to improve the knowledge of the course while 43.7 percent was in doubt of it and thus asserting that active participation has nothing to do with improving knowledge of the course. Among the active participants, 86.7 percent believed that active participation in practical improve the knowledge of the course whereas 13. 3 percent were in doubt of the fact that practical session improves the knowledge. In contrary to this, among the non-actively participating students, about 70.6 percent believed that practical sessions do not improve knowledge of the course where only24.9 percent were against this and believed that practical sessions improve the knowledge. The proportion of students who did not believe that practical sessions improve the course knowledge was higher among non- actively participating students suggesting that, such a knowledge based negative perception would deter students not to actively participate in practical sessions. The proportional difference was statistically significant at 1 percent significance level. 
Regarding suitability of the time, the results indicated that, from the overall student, 25 percent and 43.7percent of the students believed that practical sessions were good when the scheduled time is in the morning and in the afternoon respectively. The remaining 31.3 percent attends practical sessions indifferent of its time schedule. Both among the actively and non-actively participating students, about 40 percent and 47 percent of the sampled students preferred afternoon sessions respectively for their practical sessions. Students would prefer practical classes in the afternoon as an alternative to theoretical classes.

In the morning, due to its cool temperature, students would enjoy theoretical classes. They feel afresh in the morning and ready to learn theories. But in the afternoon, it could be difficult to attend theoretical classes due to the fact that, with the relatively hot temperature of the environment, students feel tiresome and asleep. In such a case on the afternoon practical class would be preferable.

Another key factor that could affect students' active participation is mode of teaching. Form total sample, 43.8 percent, 28.1 percent and 28.1 percent of the respondents believed that the teaching methods being used in practical classes were teacher centered, mix of both teacher and student centered, and student centered respectively. Among the active participants, 40 percent of the sampled students stated that the teaching method being practiced in practical sessions was student centered while 33.3 percent believed that it was student centered. The remaining 26.7 percent believed that the teaching methods being was used a mix of both teacher centered and student centered. Among the non-actively participating students, about 47.1 percent of the respondents believed that the teaching methods $b$ was practiced with teacher centered. This proportion was slightly larger compared to the proportion of those with actively participating students. From this it is logical to deduce that using teacher centered teaching method would discourage students not to actively participate in practical sessions.

Table 1: Result of Descriptive Statistics

\begin{tabular}{|c|c|c|c|c|c|}
\hline Variables & \multicolumn{4}{|c|}{ Students active participation } & \multirow{4}{*}{$\begin{array}{c}\text { Chi2-value } \\
0.001^{* * *}\end{array}$} \\
\hline \multirow{4}{*}{$\begin{array}{l}\text { Frequency } \\
\text { participation }\end{array}$} & Components & $\begin{array}{c}\text { Participant } \\
N=15(53.1)\end{array}$ & $\begin{array}{c}\text { Non participant } \\
N=17 \text { (46.9) }\end{array}$ & Total & \\
\hline & Always & $10(66.7 \%)$ & $2(11.8 \%)$ & $12(37.5 \%)$ & \\
\hline & Sometimes & $5(33.3 \%)$ & $15(88.2 \%)$ & $20(62.5 \%)$ & \\
\hline & Total & $15(100 \%)$ & $17(100 \%)$ & $32(100 \%)$ & \multirow{3}{*}{$0.035^{* *}$} \\
\hline \multirow[b]{3}{*}{ Encouragements } & Yes & $10(66.7 \%)$ & $5(29.4 \%)$ & $15(46.9)$ & \\
\hline & No & $5(33.3 \%)$ & $12(70.6 \%)$ & $17(53.1)$ & \\
\hline & Total & $15(100 \%)$ & $17(100 \%)$ & $32(100 \%)$ & \\
\hline \multirow{4}{*}{$\begin{array}{l}\text { Students attitudes } \\
\text { towards practical }\end{array}$} & Excellent & $9(60 \%)$ & $7(41.2 \%)$ & $16(50 \%)$ & \multirow{3}{*}{$0.010 * * *$} \\
\hline & V. good & $5(33.3 \%)$ & $1(5.9 \%)$ & $6(18.8 \%)$ & \\
\hline & Good & $1(6.7 \%)$ & $9(52.9 \%)$ & $10(31.2 \%)$ & \\
\hline & Total & $15(100 \%)$ & $17(100 \%)$ & $32(100 \%)$ & \multirow{3}{*}{$0.001 * * *$} \\
\hline \multirow{3}{*}{$\begin{array}{l}\text { Students' } \\
\text { perception of } \\
\text { whether practical } \\
\text { can improve } \\
\text { knowledge? }\end{array}$} & Yes & $13(86.7 \%)$ & $5(29.4 \%)$ & $18(56.3 \%)$ & \\
\hline & No & $2(13.3 \%)$ & $12(70.6 \%)$ & $14(43.7 \%)$ & \\
\hline & Total & $15(100 \%)$ & $17(100 \%)$ & $32(100 \%)$ & \\
\hline \multirow[b]{4}{*}{ Suitable time } & Morning & $4(26.7 \%)$ & $4(23.5 \%)$ & $8(25 \%)$ & \multirow{3}{*}{0.922} \\
\hline & Afternoon & $6(40 \%)$ & $8(47.1 \%)$ & $14(43.7 \%)$ & \\
\hline & Both & $5(33.3 \%)$ & $5(29.4 \%)$ & $10(31.3 \%)$ & \\
\hline & Total & $15(100 \%)$ & $17(100 \%)$ & $32(100 \%)$ & \\
\hline \multirow{4}{*}{$\begin{array}{l}\text { Teaching methods } \\
\text { being used }\end{array}$} & St. centered & $5(33.3 \%)$ & $4(23.5 \%)$ & $9(28.1 \%)$ & \multirow{4}{*}{0.825} \\
\hline & T. centered & $6(40 \%)$ & $8(47.1 \%)$ & $14(43.8 \%)$ & \\
\hline & Both & $4(26.7 \%)$ & $5(29.4 \%)$ & $9(28.1 \%)$ & \\
\hline & Total & $15(100 \%)$ & $17(100 \%)$ & $32(100 \%)$ & \\
\hline
\end{tabular}

Note: $* * *$ and ${ }^{* *}$ shows significance at $1 \%$ and $5 \%$ probability level respectively

\subsection{Results of the Econometric Analysis}

Using econometric statistical tool, the results indicated that participation frequency, student attitudes for practical session and their perception of whether practical session class improves the knowledge of the course were significantly affected students' active participation in practical classes. The marginal effect of participation frequency affected active participation in practical classes negatively at 5 percent probability level. A student who attends practical classes always increasing by one percent has a probability decreasing active participating in practical classes by about 67.8 percent compared to the one who attends practical's sometimes. This is may be due to the existing boring teaching-learning style in the classes, a student who regularly attends practical classes could be discouraged to actively participate in the sessions. Sometimes, teachers could also give more focus to passive 
students to encourage them to actively participate in classes. This could make actively participating students passive if not done in a balanced way with caution.

Positive attitudes toward practical classes increased by one percent, the probability of actively participating in practical classes increasing by about 25.1 percent than one who have negative attitudes. A student with positive attitude towards practical classes actively participates more in practical sessions compared to the one with negative attitude. Positive attitude encourages students to actively engage in all class activities. The results were positively and significant at 10 percent probability level. Positive attitudes for practical classes to improving the course knowledge increased by one percent possibility of actively participating in practical classes increasing by about 55.1 percent compared to those who think that practical class does not improve knowledge of the course. It is logical to conclude that a student who believes that he/she can get knowledge from the practical session would actively participate in every class activities. The results were positively and significant at 5 percent of significance level.

Table 2: Results of the Logit Econometric model

\begin{tabular}{lccccc}
\hline Active participation & Coefficients & $\mathbf{d y} / \mathbf{d x}$ & Std. Err. & $\boldsymbol{z}$-values & p-values \\
\hline Participation frequency & -4.483 & -0.678 & 2.26 & -1.984 & $0.047^{* *}$ \\
Encouragements by instructors & 2.368 & 0.358 & 1.492 & 1.587 & 0.112 \\
Attitude towards practical classes & 1.663 & 0.251 & 0.987 & 1.686 & $0.092^{* * *}$ \\
Whether practical can improve knowledge of & & & & & \\
course & 3.646 & 0.551 & 1.855 & 1.965 & $0.049^{* *}$ \\
Time suitability & -0.511 & -0.077 & 0.65 & -0.786 & 0.432 \\
Teach methods & -0.025 & -0.004 & 0.598 & -0.042 & 0.966 \\
Constant & 1.992 & & 2.468 & 0.807 & 0.419 \\
\hline
\end{tabular}

Note:**and ${ }^{* * *}$ shows significance at $5 \%$ and $10 \%$ probability level respectively

\section{Action Taken as intervention for implementation}

What did we do?

According to the above descriptive and econometric research results, the following measures should be taken as intervention tool in order to encourage students actively participate in practical session classes. The objective of our intervention is to encourage interests of students towards active participation in practical session.

We aware teachers with the following issue

$\checkmark$ Teachers can offer a briefing session to explain to the class the basic theoretical background, learning outcomes, and the required techniques of the particular lesson.

$\checkmark \quad$ The teacher gives teaching materials in advance with discussion questions that enable students to prepare themselves and actively participate in the class.

$\checkmark \quad$ Teacher shall give chance for all students to revise the previous class at the beginning of practical session and also give introduction about the next topic at the end of each practical session class.

$\checkmark \quad$ The teacher shall express the knowledge and skill in more simple and understandable language for each student in practical session class and additionally outside the class if required.

$\checkmark \quad$ The teacher shall give incentives as a form of reward like mark, applaud, and give prizes like pane and paper for students who are actively participating in practical session.

$\checkmark$ The teacher shall improve student centered teaching learning process using different active teaching methods like group discussion, presentation, give discussion questions which are related with their real life situations and debate.

\section{We aware student with the following issue}

$\checkmark$ We aware students how working together is crucial and the spirit of team work.

$\checkmark$ We tried to create awareness about the advantage of active participation, and student center teaching is the duet of student and which help to progress to share new ideas with their friends, develop selfconfidence, communication skill and of practical session class to link theories and practice in class

$\checkmark \quad$ We gave advice for students who afraid to actively participate in practical session class

How can we evaluate our Work?

We used the following strategies to evaluate the effectiveness of our intervention

\section{Observation}

We observed that almost all students were actively participating, showing interest and feeling responsible for their work in their practical session after intervention.

\section{Questionnaire}

We distributed a questionnaire for all students from animal production and technology students regarding their average score in tests and quiz results before and after implementation. The students 'responses of their average scores before and after interventions were summarized in the following table. 
Table 3: Student average score before and after implementation of our intervention

\begin{tabular}{|l|l|l|l|}
\hline Assessments & & Before implementation & After implementation \\
\hline \multirow{3}{*}{ Quiz (5\%) } & Overall result score & 3.14 & 3.79 \\
\cline { 2 - 4 } & Non active participant (17) & 2.88 & 3.56 \\
\cline { 2 - 4 } & Active Participant (15) & 3.43 & 4.07 \\
\hline \multirow{3}{*}{ Tests (10\%) } & Overall result score & 5.84 & 7.07 \\
\cline { 2 - 4 } & Non active participant (17) & 5.24 & 6.59 \\
\cline { 2 - 4 } & Active part participate (15) & 6.52 & 7.62 \\
\hline
\end{tabular}

As table 3 shows that the average score of the student with in quiz from 5\% was 3.14 and 3.79 before and after implementation of our intervention respectively. In addition to this, students who were actively participated in practical session scored $3.43 \%$ and $4.07 \%$ before and after implementation of our intervention respectively and also students who were not actively participated were scored $2.88 \%$ and $3.56 \%$ before and after implementation of our intervention respectively.

As the same time the average score of the overall student within their own test result was $5.84 \%$ and $7.07 \%$ before and after implementation of our intervention respectively. Students who were actively participated scored $6.52 \%$ and $7.62 \%$ before and after implementation of our intervention respectively and also students who were not actively participated were scored $5.24 \%$ and $6.59 \%$ before and after implementation of our intervention respectively.

After put in to practices the actions recommended by we, the research found that implemented strategies bring some important changes such as enhanced students participation, applied various active learning methods, encouragement by the instructor, high participation of students using their own language, improved student selfconfidence and as result the average score of student was better for both active participants and non participants due to implementation of our intervention.

\section{Conclusion and Recommendation \\ 7.1 Conclusion}

Educations play the significant role for the economic growth and development in Ethiopia. As result currently, Ethiopia is enchanting different measures to use education for the source of economic growth and development. Even though education play it contribution for economic grow and development, as study result show that about 37.5 percent of the respondents was always participate in practical classes and The remaining 62.5 percent attends practical classes sometimes. According to encouragements by teacher, from the overall student, 46.9 percent of the students revealed that their instructors provided them different encouragement advice on practical classes. The remaining 53.1 percent have reported that they have not got encouragement advice from their instructors. As student stated regarding to attitudes towards practical classes, among the actively participating students, 60 percent believed that active participation in practical classes was excellent while 33.3 percent and 6.7 percent believed that practical session is very good and good respectively. From the total sampled student, 56.3 percent believed that active participation in practical sessions help to improve the knowledge of course while 43.7 percent was in doubt of it and thus asserting that active participation has nothing to do with improving knowledge.

As the study result indicated that from the total sample, 25 percent and 43.7 percent of the students believed that practical sessions were good when the scheduled time was in the morning and in the afternoon respectively. The remaining 31.3 percent attends practical sessions indifferent of its time schedule. In addition to above research result 43.8 percent, 28.1 percent and 28.1 percent of the respondents stated that the teaching methods being used in practical classes were teacher centered, mix of both teacher and student centered, and student centered respectively.

According to the estimated logit model indicated, attitudes toward practical classes, attitudes for practical classes to improving the course knowledge were positively and statically significant at 10 percent and 5 percent respectively. But the marginal effect of participation frequency affected active participation in practical classes negatively at 5 percent of probability level.

After taken different intervention strategy, as table 3 show that the average scores of the student with in quiz from 5 percent was 3.14 and 3.79 before and after implementation of our intervention respectively and also the average score of the overall student within their own test result was 5.84percent and 7.07percent before and after implementation of our intervention respectively.

\subsection{Recommendation}

According to the findings of the research, all the above intervention strategies should be implemented with maximum caution. The university as well as any other concerned body like teacher should be consistently encouraged and set as mains pillar strategies to mitigate factors that influence student active participation in practical session. 


\section{Reference}

Brody, M. (2006).Montana State University, faculty.Retrieved from the web http://arexpeditions.montana.edu/index.php, Jan, 2008.

Borg, W. (1965).Applying educational research: A practical guide for teachers. New York: Longman.

Elliot, J. (1991). Teachers as researchers: Implications for supervision and for teacher education. Teaching and Teacher education, 6(1)

Gujarati, D.N. 1988. Basic Econometrics,Second Edition, McGraw Hill, Inc. New York

Maddala, G.S. 1992 Introduction to Econometrics: 2nd Edition. University of Florida and Olio State University. Asimon and Schuster Company Englewood cliffs, Newjersy

Mills, G. E. (2003). Action research: A guide for the teacher researcher. Upper Saddle River, NJ: Merrill/Prentice Hall.

Watts, H. (1985). When teachers are researchers, teaching improves. Journal of Staff Development, 6 (2), 118127. 